\title{
Yeah, right, whatever
}

\author{
Stephen Hancocks OBE \\ Editor-in-Chief
}

I have always promised myself that as soon as I became aware of starting a sentence with the phrase, 'when I was your age...' when talking to a younger person, I would mentally check myself and ask if the point I was about to make was strictly necessary. I recall how frustrating and tiresomely dreary it was to have to listen to some 'wise person' droning on about the old days when, frankly, what did they know about anything of the here and now? My regret is that by switching off then, I probably missed a great deal of very valuable advice and so if I can find a way to convey my knowledge without sounding ancient then I figure it might be of help. Well, maybe.

The reason for raising the subject is that I am not sure whether the change in the behaviour and attitudes of young people, and specifically in this context dental students and young dentists, is a feature of youth per se or of our society's changing values and priorities with which they have been brought up. We might usefully take two examples here which are often regarded as litmus tests for acceptability; dress and common courtesy.

I was told recently of a patient's comment regarding a young dentist who was wearing trainers in the surgery. That alone wasn't the issue, it was the fact that the trainers were so worn that the practitioner's sock was showing through the front. But that wasn't the misdemeanour either, it was that the sock had a hole in it allowing the dentist's big toe to be seen, which the patient really thought was 'a bit much'. Granted, it is an extreme, anecdotal example but one only has to take a glance around a lecture room, a day's training course or a seminar to appreciate that dress codes and styles have changed enormously. Out have gone suits, ties, jackets, skirts and dresses in favour of smart casual, or the not-so-smart-casual of torn jeans, tee shirts, baseball caps; yeah, right, whatever.

\section{GRUMPY OLD MAN SYNDROME?}

From the behavioural point of view I am less certain that it is only young people whose sense of etiquette and politeness has begun to evaporate. Over the last twenty years or so I have chaired, compèred, introduced and presented a large variety of meetings, debates, ceremonies, awards evenings, conferences, lectures and conventions but the single most striking factor is that audiences no longer sit politely and listen. It might just be me but I do now observe it in many walks of life, at media awards, at dinners, AGMs, charity events. While the speaker is trying to communicate, the audience is busy in its own world, chatting, drinking, socialising, anything but paying in my mind the common courtesy of polite attention.

Of course, as I hinted earlier, all of this may just be grumpy old man syndrome but I fall back on the defence that there is also a wider relevance. The General Dental Council (GDC) in its role of protecting the public is also something of a guardian of standards and these considerations necessarily touch on the same topics. Currently the Council is consulting on the Student Fitness to Practise Guidance and in the further future, as highlighted on this page recently, the colossus of revalidation will be delivered upon us with the need to be able to quantify professionalism; but crucially before that, how to define it.

So, what do patients expect and what should we expect as far as inter-professional respect and professionalism are concerned? We cannot practise our profession in isolation from society. Running a business as if we were in the 1930s and using the same equipment and materials might have a novelty value but would be totally impractical, unsafe and inappropriate. So why should we expect manners to be any different in their development as compared to technical advances? Perhaps the answer lies in respect for our fellow human beings and for our fellow team members. The GDC's guidelines for standards in professionalism outline many of the definable issues such as consent, confidentiality and honesty but there needs to be some measure of respect over and above this, some lesseasily definable but nonetheless crucially important ingredient which marks us out as being different enough to warrant the accolade 'professional'.

The world at present does not take kindly to the epithet professional. No more stark evidence is needed than that the powers that be have by stealth, and with scant opposition from ourselves, removed the mechanisms by which we are self-governing; instituting instead the politically mediated and more conveniently controlled expedients of selection and appointment over the relative vicissitudes of the ballot box. Perhaps then we need to look at our behaviours, our own regard for one another and our own sense of respect before we can expect it from others. It may find immediate instances among young people, it may be a societal shift but unless we regard it with due seriousness it may yet swallow us up in a maelstrom of mediocrity. Young people may not fully appreciate the importance of this, ...but when I was their age...

DOI: 10.1038/sj.bdj.2009.273 